EDUR・Educação em Revista. 2020; 36:e224517

DOI: http://dx.doi.org/10.1590/0102-4698224517

(9) (1) https://creativecommons.org/licenses/by/4.0/

ARTIGO

\title{
PESQUISA ESCOLAR NOS ANOS INICIAIS DO ENSINO FUNDAMENTAL: O QUE DIZEM OS PROFESSORES?
}

\author{
DIEGO GERÔNIMO SILVA ${ }^{1}$ \\ ORCID: https://orcid.org/0000-0003-4770-2774 \\ REGINA MARIA ROVIGATI SIMÕES ${ }^{2}$ \\ ORCID: https://orcid.org/0000-0002-3135-9425 \\ DANIEL BOVOLENTA OVIGLI ${ }^{3}$ \\ ORCID: https://orcid.org/0000-0002-4057-547X
}

\begin{abstract}
RESUMO: O presente estudo objetivou mapear a visão de docentes dos anos iniciais do Ensino Fundamental acerca da inserção da pesquisa escolar em suas práticas pedagógicas. A investigação utilizou abordagens qualitativa e quantitativa e foi realizada com 124 professores, do $1^{\circ}$ ao $5^{\circ}$ ano do Ensino Fundamental, os quais responderam a um questionário estruturado. $\mathrm{O}$ tratamento dos dados foi feito pelo software Iramuteq. Os resultados mostraram que a pesquisa escolar é um recurso benéfico às práticas de ensino e proporciona aos alunos vivências com projetos e atividades concretas, contribuindo para o desenvolvimento de atitudes críticas, curiosas e reflexivas. Contudo, dificuldades como o pouco acesso aos meios de informação (principalmente internet), falta de compromisso discente, a escolha das temáticas e os hábitos de leitura foram indicados pelos professores, mas, ao mesmo tempo, o auxílio para a aprendizagem, a curiosidade por assuntos da atualidade e a participação ativa foram indicados como facilitadores do trabalho docente.
\end{abstract}

Palavras-chave: Anos iniciais do Ensino Fundamental, professor, estudante, pesquisa escolar.

\section{SCHOOL RESEARCH AT ELEMENTARY SCHOOL: WHAT DO TEACHERS SAY?}

\begin{abstract}
This study aimed to map the view of teachers from the first years of elementary school about the insertion of school research in their teaching practices. The research used qualitative and quantitative approaches and had been done with 124 teachers from 1st to 5th years of elementary school, who answered a structured questionnaire. Data processing was done by Iramuteq software. The results showed that school research is a beneficial resource for teaching practices and provides students with concrete projects and activities, contributing to the development of critical, curious, and reflective attitudes. However, difficulties such as poor access to the means of information (mainly internet), lack of student commitment, the choice of themes and reading habits were indicated by the teachers but, at the same time, the learning support, the curiosity about current affairs and active participation were indicated as facilitators of teaching work.
\end{abstract}

\footnotetext{
${ }^{1}$ Universidade Federal do Triângulo Mineiro. Uberaba, MG, Brasil. < diego-silva@hotmail.com.br>

2 Universidade Federal do Triângulo Mineiro. Uberaba, MG, Brasil. <rovigatisimoes@uol.com.br>

${ }^{3}$ Universidade Federal do Triângulo Mineiro. Uberaba, MG, Brasil. < daniel.ovigli@uftm.edu.br> Educação em Revista|Belo Horizonte|v.36|e224517|2020
} 
Keywords: Early years of elementary school, teacher, student, school research.

\section{TAREAS ESCOLARES DE INVESTIGACIÓN EN LOS PRIMEROS ANÕS DE LA ESCUELA PRIMÁRIA: ¿QUÉ DICEN LOS MAESTROS?}

RESÚMEN: El presente estudio tiene como objetivo mapear la percepción de los maestros que trabajan en los años iniciales de la escuela primaria sobre la inclusión de tareas escolares de investigación en sus prácticas docentes. El abordagen investigativo ha sido mixto a partir del análisis qualitativo y quantitativo. La muestra de participantes corresponde a 124 profesores del $1^{\circ}$ hasta el $5^{\circ}$ año de la escuela primária. Para llevar a cabo la investigación los profesionales contestaron un cuestionario estruturado. Los datos fueron analisados con la utilización del software Iramuteq. En primer lugar, cabe señalar que las tareas de investigación en el contexto de la escuela es un recurso que trae beneficio a las prácticas educativas y proporciona a los alumnos vivencias con otros proyectos y actividades concretas. Eso contribuye con el desarrollo de actitudes críticas, originales y reflexivas. Sin embargo, algunas dificultades fueron apuntadas por los profesores, tales como: poco acceso a los medios de información, sobretodo internet; falta de interés discente; elección de temas para proyectos. De otro modo, la ayuda al proceso de aprendizaje, la investigación de temas de la actualidad y la participación han sido indicados como facilitadores del trabajo docente.

Palabras clave: Primeros años de la escuela primaria, profesor, alumno, tareas escolares de investigación. 


\section{INTRODUÇÃO}

Estudos desenvolvidos nos últimos dez anos (BAGNO, 2008; KISTNER, 2008; PERTICARRARI et al., 2010; PANIAGO; ROCHA; PANIAGO, 2014; OLIVEIRA, 2015; OLIVEIRA; CAMPELLO, 2016) mostram que utilizar a pesquisa em sala de aula, também denominada pesquisa escolar, é uma forma de buscar novos conhecimentos, informações, proporcionar diálogos e debates sobre conteúdos disciplinares, contribuir para (re)construir o conhecimento e a autonomia e organizar a prática docente.

A pesquisa é um componente constituinte para a construção do conhecimento nas instituições de ensino do Brasil, conforme a Lei no 9.394/96 que estabelece as Diretrizes e Bases da Educação Nacional - LDBEN, especificamente em seu artigo $3^{\circ}$ que trata dos princípios norteadores do ensino. A pesquisa aparece no segundo princípio, “[...] liberdade de aprender, ensinar, pesquisar e divulgar a cultura, o pensamento, a arte e o saber" (BRASIL, 1996). Ainda sobre este tema, o trecho do texto que trata da forma de integrar disciplinas curriculares, como proposto no parágrafo $7^{\circ}$ do artigo 26 , apresenta que "A integralização curricular poderá incluir, a critério dos sistemas de ensino, projetos e pesquisas envolvendo os temas transversais [...]" (BRASIL, 1996).

Para corroborar com essa denotação da palavra "pesquisa”, Diniz-Pereira e Lacerda (2009) indicam que, como polissêmica, pode expressar muitos significados e diferentes aplicações, dependendo de quem a manipula. Ao ser relacionada como atividade científica, a palavra pesquisa estabelece rumos que a caracterizam como tal, e dialogam com o paradigma no qual se inscreve e que tenta conhecer um determinado objeto, ao socializar o conhecimento aprendido nos componentes curriculares.

A cada nova prática de integralização curricular em sala, novas experiências perfazem a liberdade de aprender e, a cada momento, a reprodução automática das aulas fica para trás devido às novas configurações de conhecimento e aplicação destes, o que configura uma motivação para o trabalho com este recurso pedagógico nos anos iniciais da Educação Básica. A pesquisa por conteúdos didáticos distribuídos pelos componentes curriculares e que atraiam os discentes, nesse momento, é imprescindível, pois proporciona a percepção para reformular os saberes aprendidos por meio de diferentes temas transversais.

Ademais, Galiazzi e Moraes (2002) e Ninin (2008) afirmam que uma educação por meio da pesquisa promove a transformação dos educandos em sujeitos das interfaces pedagógicas, dispondo de autonomia com capacidade para a construção de competências e articulação de práticas autorais, capazes de prover argumentações com propriedade e, dessa forma, possibilitar a emergência de pensamentos críticos, autônomos e reflexivos.

Bagno (2008) reflete que o docente, ao ensinar, aprende no cotidiano da sala de aula, e promove inúmeras possibilidades para que o discente busque e alce sozinho as fontes do conhecimento que estão dispostas na sociedade moderna. Contudo, não deve apenas mostrar as alternativas, mas ser um mediador e oferecer suporte, orientação e direcionamento ao aluno para que ele potencialize um olhar crítico e consiga escolher as fontes de conhecimento e de informação fidedignas.

Compreender a pesquisa escolar como alicerce da educação e não de aula - simples interação entre docente e discente - é apreender que o conhecimento não é fim, mas meio. Para que esse conhecimento se torne educativo, há a necessidade de orientação, tendo ética e valores como pilares dos fins almejados (DEMO, 2015). A interação entre professor e aluno precisa ser orientada para que esse conhecimento construtivo seja (re)configurado no cotidiano da sala de aula, por meio do diálogo e da mediação para induzir o aluno ao questionamento, envolvendo e interpretando o contexto que engloba a pesquisa, o qual só se articula quando há conscientização de ambas as partes na percepção do processo (OLIVEIRA; GONZAGA, 2012).

O uso da pesquisa em sala de aula não apresenta um único caminho, todavia é determinada por diretrizes. Assis e Teixeira (2009), por exemplo, acreditam que o professor precisa abarcar, dentre outros elementos, a motivação do discente, orientando-o e fazendo com que a pesquisa seja parte do cotidiano de ambos. O aluno pode, então, ter despertado seu interesse para ser ator na construção de sua aprendizagem, ao desenvolver um espírito crítico, como personagem ativo nesse processo, e dedicandose juntamente com o professor. 
Para utilizar a pesquisa na sala de aula é necessário que o professor questione seus alunos para identificar conhecimentos prévios a partir de suas vivências de mundo (experiências e aprendizados) e os estimule a participar desta experiência, assim como dialogar e apontar caminhos de como suas vivências podem ser trabalhadas para que a aprendizagem tenha sentido (PERTICARRARI et al., 2010). em um trabalho

A pesquisa não deve se caracterizar, conforme destacam Oligurski e Pachane (2010, p. 255),

[...] maçante ou como uma cópia de trechos de livros e enciclopédias - ou, com o advento do computador, com o uso indiscriminado do "CTRL C + CTRL V" -, mas como atividade básica no processo de apropriação dos conhecimentos escolares, pois, por meio dela, busca-se oferecer o acesso ao conhecimento historicamente acumulado. Por meio da pesquisa, o ensino e aprendizagem podem ser pensados além de um conjunto de conhecimentos sistematizados e apresentados por meio de livros didáticos, que, muitas vezes, desconsideram o contexto escolar dos alunos.

Nessa proposta é indispensável que o professor assuma uma postura que envolva ações conjuntas e articuladas entre ele e o aluno, com o compromisso formal e político para o desenvolvimento de competências. Precisa aprender a perceber os ruídos e os silêncios de seus alunos necessitando ser, em sala de aula, um mediador, de modo a levar o aluno a ter maior participação, questionamento, espírito crítico e autonomia (PERTICARRARI et al., 2010).

Assim, a pesquisa não é um ato isolado, mas requer que o docente, em sua função de "[...] mediador, abra novos caminhos para seus alunos em direção à investigação, questionando-os e permitindo que questionem, visando a ultrapassar o saber superficial pautado no acúmulo de informações" (NININ, 2008, p. 21).

De acordo com Vasconcelos; Praia e Almeida (2003), a proposta do ensino por pesquisa elucida conteúdos inter e transdisciplinares, culturalmente e educacionalmente relevantes (uma vez que os propósitos educacionais devem ser valorizados), afirmam que a pesquisa em sala de aula deve trazer à tona as vivências e o conhecimento que os alunos carregam do meio em que vivem (casa) e estão inseridos.

Os mais variados conhecimentos do cotidiano são abarcados pelos saberes populares que constituem a vida de muitos alunos e precisam ser sondadas pelo professor em seu trabalho, evidenciados quando propõe pesquisas sobre fatos da realidade do aluno. A pesquisa deve ser utilizada em sala de aula com vários papéis dentro da educação, contudo, se não houver um preparo docente para a utilização desse instrumento, não há trabalho consistente focado no aprendizado (KISTNER, 2008).

Há que se considerar que tampouco a pesquisa se constitui em um processo milagroso ou fórmula salvadora da educação no Brasil, mas ela é vista como um instrumento com vistas a promover o desenvolvimento do pensamento, uma vez que estimula o questionamento, a reflexão, a descoberta, a análise, a argumentação, a criatividade e a criticidade entre as partes e mediada pelo trabalho do professor em sala de aula.

Isso posto, e procurando entender como professores dos anos iniciais do Ensino Fundamental compreendem a pesquisa escolar no contexto de suas práticas de ensino, o presente artigo é proveniente da dissertação de mestrado intitulada "A pesquisa escolar na visão de professores dos anos iniciais do Ensino Fundamental: um estudo na rede municipal de ensino de Uberaba/MG", defendida junto ao Programa de Pós-Graduação em Educação da Universidade Federal do Triângulo Mineiro (PPGE/UFTM), e teve como objetivo mapear a visão de docentes dos anos iniciais deste nível de escolarização acerca da inserção da pesquisa escolar em suas práticas pedagógicas.

Trata-se de uma investigação fundamentada em uma abordagem de cunho quali-quantitativo (CRESWELL, 2010), desenvolvida em 21 escolas da rede municipal de ensino de Uberaba/MG e que contou com a participação de 124 professores, os quais responderam a um questionário estruturado. $\mathrm{O}$ material empírico contruído nessa etapa foi interpretado utilizando-se a análise de conteúdo (BARDIN, 2011) com o suporte do software Iramuteq, que proporciona explorações poderosas de corpus textuais e possibilita a construção de categorias naturais, a partir do uso de técnicas estatísticas no campo das pesquisas qualitativas (CAMARGO; JUSTO, 2013). 


\section{A PESQUISA ESCOLAR E A PRÁTICA DOCENTE}

Pietrocola (2005) afirma que a ciência, enquanto corpo de conhecimentos, é internalizada intelectualmente se puder ser percebida em interface com o mundo que nos rodeia. Assim, as diferentes áreas que compõem o currículo necessitam ser consideradas como recurso à leitura e à ação no mundo. Nesse contexto, a pesquisa escolar é sinalizada como uma possibilidade de trazer os conhecimentos escolares para mais perto dos estudantes da Educação Básica, em especial dos anos iniciais, foco de ação dos professores que integraram a pesquisa que originou este artigo.

Ensinar, a partir do emprego da pesquisa escolar, implica ensino mais integrado, uma vez que não se pensa em disciplinas estanques, mas em problemas a serem refletidos, o que se torna mais profícuo ao considerar os anos iniciais do Ensino Fundamental, nos quais atua um professor multidisciplinar para os componentes curriculares. Para o trabalho com a pesquisa escolar, o estudante pode ser protagonista na busca por informações, ao desenvolver o registro e a expressão escrita, daí a necessidade de que o papel do professor se materialize enquanto mediador e orientador neste processo.

A pesquisa escolar também é apontada como instrumento para incrementar o processo educacional e como contraponto à aprendizagem tradicional, teórica e descontextualizada (HERNANDÉZ, 1998). Adicionalmente, propicia condições para incorporação da dimensão afetiva na formação dos estudantes. Para Nogueira (2003), a pesquisa escolar coloca-se também como fonte para aprofundamento, análise e criação de novas hipóteses ao buscar a construção de mais informações, fontes e detalhamentos para que, ainda, os estudantes possam encontrar diferentes estímulos no desenvolvimento de suas competências.

Assim, o trabalho com projetos possibilita o desenvolvimento de competências, a proposição de tarefas complexas e desafios que estimulem os estudantes a mobilizar e complementar seus conhecimentos. Uma possibilidade para o trabalho na perspectiva dos projetos fundamenta-se em partir de uma situação-problema, levando adiante um processo de aprendizagem que apresenta interfaces com o mundo exterior à escola, de modo a oferecer alternativas à fragmentação trazida pela disciplinaridade presente no contexto escolar (NOGUEIRA, 2003).

Em uma concepção contemporânea de pesquisa escolar, busca-se que os envolvidos participem de forma ativa na (re)construção dos conhecimentos científicos. Visa, portanto: (i) possibilitar aos participantes levantar e testar hipóteses e (ii) desenvolver a capacidade de observação, de descrição de fenômenos e de reelaboração de explicações causais para o observado (ARAÚJO; ABIB, 2003).

Cabe destacar que a literatura educacional vem demonstrando que os estudantes são motivados e tem a aprendizagem potencializada quando participam ativamente de abordagens que consideram a pesquisa como princípio educativo, em especial quando a origem do problema de pesquisa é proveniente dos interesses dos discentes (ARAÚJO; ABIB, 2003; CARVALHO, 2004; MUNFORD; LIMA, 2007; PENA; RIBEIRO FILHO, 2009; CARVALHO et al., 2013). As características que perfazem a abordagem investigativa na pesquisa escolar incluem (i) a elaboração do problema, (ii) o trabalho com hipóteses e o planejamento da investigação, (iii) a leitura de materiais informativos diversos, (iv) a socialização com os pares e (v) a apresentação e argumentação das soluções encontradas (ZÔMPERO; LABURÚ, 2011).

O trabalho com a pesquisa escolar prevê um processo contínuo que busca identificar, investigar e analisar a construção do conhecimento que se processa na interação do participante com o conhecimento. Tendo por base as perspectivas de avaliação formativa, faz-se necessário ter em consideração na avaliação de uma proposta didática que faça uso de pesquisa escolar: (i) participação ativa dos estudantes nas discussões propostas, (ii) leitura, condução e socialização de textos propostos entre os pares, (iii) relatório de atividades (englobando: relato das atividades práticas, conclusões e erros apresentados na execução da pesquisa).

Essa asserção é aderente ao que pontuam Grabauska e Bastos (2001), ao reforçarem a necessidade de que tanto professor quanto estudantes posicionem-se como pesquisadores, tirando do primeiro a centralidade do ato educativo uma vez que é em conjunto, na interação, que conhecimentos são construídos. 
Nesse processo o professor atua como organizador de aprendizagens, mediando relações entre eventuais professores integrantes da pesquisa escolar a ser desenvolvida, entre professor e aluno e entre alunos. Segundo Zanolla (2008, p. 45), a pesquisa escolar se coloca para "resolver problemas, colocar questões, traçar objetivos, apontar para a necessidade de realizar atividades; enfim, proporcionar um caráter de responsabilidade".

O docente disposto a integrar a pesquisa escolar às suas práticas pedagógicas apresenta como primeiro passo da sua ação pedagógica a flexibilidade, pois em uma perspectiva de trabalho diferenciada, como a proposta por uma pedagogia da pesquisa, visa ao rompimento do isolamento dos participantes e a segmentação dos conteúdos, típica do ensino tradicional, o que pode gerar resistências, seja de estudantes, pais, professores e, porque não, de si próprios.

Demo (1994) destaca a pesquisa como caminho metodológico na Educação Básica, sendo necessária a distinção entre pesquisa como princípio científico e a pesquisa como princípio educativo. Trata-se de pensar, como mencionado no parágrafo anterior, a pesquisa como pedagogia, como modo de educar, e não apenas como construção meramente técnica do conhecimento. A pesquisa sinaliza a educação questionadora, a formação do indivíduo para que ele saiba pensar. Já a pesquisa científica é apontada por Demo (1994) como um conjunto de ações propostas para encontrar a solução para um problema que tem por base procedimentos racionais e sistemáticos e é realizada quando se tem um problema e não se tem informações para solucioná-lo.

Ao discutir pesquisa escolar, particularmente nos anos iniciais, busca-se em Moura e Barbosa (2007) as tipologias possíveis de projetos no contexto escolar, que incluem projetos de desenvolvimento, projetos de ensino, projetos de trabalho, projetos de intervenção e projetos de pesquisa, sistematizados no Quadro 1.

Quadro 1. Tipos de projetos na área educacional

\begin{tabular}{|c|c|c|}
\hline Tipo & Caracterização & Exemplos/Fases \\
\hline $\begin{array}{l}\text { Projetos de desenvolvimento } \\
\text { ou de produto }\end{array}$ & $\begin{array}{l}\text { Estão inseridos em um sistema } \\
\text { ou organização e visam à } \\
\text { elaboração de um "produto" }\end{array}$ & $\begin{array}{lrr}\text { Novos materiais } & \text { didáticos; } \\
\text { nova organização } & \text { curricular; } \\
\text { novo curso; } & \text { softwares } \\
\text { educacionais } & \end{array}$ \\
\hline Projetos de ensino & $\begin{array}{l}\text { Se fazem presentes em uma ou } \\
\text { mais disciplinas e estão } \\
\text { dirigidos à melhoria do } \\
\text { processo ensino-aprendizagem } \\
\text { e dos conteúdos relativos a } \\
\text { essas disciplinas. Esses } \\
\text { projetos são próprios da área } \\
\text { educacional e referem-se ao } \\
\text { exercício das funções do } \\
\text { professor. }\end{array}$ & \begin{tabular}{lrr} 
Organização dos & \multicolumn{2}{r}{ recursos } \\
existentes na & escola ou \\
comunidade & e & melhor \\
aproveitamento & de & suas \\
possibilidades & e r de \\
desenvolvimento & curricular, \\
visando ao atendimento das \\
características do processo de \\
aprendizagem dos alunos.
\end{tabular} \\
\hline Projetos de trabalho & $\begin{array}{l}\text { Desenvolvidos por alunos em } \\
\text { uma ou mais disciplinas, sob } \\
\text { orientação de um ou mais } \\
\text { professores, e têm por objetivo } \\
\text { a aprendizagem de conceitos e } \\
\text { desenvolvimento de } \\
\text { competências e habilidades } \\
\text { específicas. }\end{array}$ & $\begin{array}{l}\text { A principal diferença entre os } \\
\text { projetos de ensino e de } \\
\text { trabalho está na ação: os } \\
\text { primeiros são executados pelo } \\
\text { professor e os segundos pelos } \\
\text { alunos, sob orientação do } \\
\text { professor, visando à aquisição } \\
\text { de conhecimentos, habilidades } \\
\text { e valores. Fases: } \\
\text { (i) Planejamento e } \\
\text { (ii) Análise da ação; } \\
\end{array}$ \\
\hline
\end{tabular}




\begin{tabular}{|c|c|c|}
\hline & & $\begin{array}{l}\text { (iii) } \begin{array}{l}\text { Comunicação dos } \\
\text { resultados. }\end{array}\end{array}$ \\
\hline Projetos de intervenção & $\begin{array}{l}\text { Visam a uma intervenção } \\
\text { propriamente dita no contexto } \\
\text { em foco, por meio da } \\
\text { introdução de modificações na } \\
\text { estrutura (organização) e/ou } \\
\text { na dinâmica (operação) do } \\
\text { sistema ou organização. }\end{array}$ & $\begin{array}{l}\text { Procura melhoria das } \\
\text { condições básicas de } \\
\text { funcionamento da escola, por } \\
\text { meio do aperfeiçoamento da } \\
\text { infraestrutura e recursos } \\
\text { humanos; de cooperação } \\
\text { interinstitucional, incluindo a } \\
\text { interação escola-universidade }\end{array}$ \\
\hline Projetos de pesquisa & $\begin{array}{l}\text { Considera a construção de } \\
\text { conhecimentos sobre } \\
\begin{array}{l}\text { determinado } \\
\text { questão ou assunto }\end{array}\end{array}$ & $\begin{array}{ll}\text { Pressupõe as fases: } \\
\begin{array}{ll}\text { (i) } & \text { Inicialização; } \\
\text { (ii) } & \text { Planejamento; } \\
\text { (iii) } & \text { Execução; } \\
\text { (iv) } & \text { Controle; } \\
\text { (v) } & \text { Encerramento. }\end{array}\end{array}$ \\
\hline
\end{tabular}

Fonte: Elaborado a partir de Moura e Barbosa (2007).

De acordo com o Quadro 1, nota-se a utilização de projetos de pesquisa na construção de conhecimentos e percebe-se que a pesquisa escolar, por meio das etapas do método científico observação, questionamento, formulação de hipóteses, experimentação, análise de dados, conclusão e divulgação - precisa estar inserida nas atividades de ensino dos anos iniciais do Ensino Fundamental. Ainda que possa não haver rigorosidade científica nesta etapa da escolarização, a pesquisa leva o estudante a inquietudes, a questionamentos, a argumentações e à construção de conhecimentos, ao partir de fatos do cotidiano e das vivências fomentadas pelo professor.

Para Martins (2005), o trabalho com projetos de pesquisa desde os anos iniciais é uma forma de evitar situações que muitas vezes ocorrem ao final de cursos acadêmicos de especialização, ou mesmo de graduações, quando o estudante se vê incapaz de realizar trabalhos de conclusão de curso, relatórios de estudos e outros trabalhos com escrita científica. O autor afirma que, ao orientar a criança a lidar com o método científico nos estudos cotidianos da sala de aula e na investigação de suas inquietudes, o professor promove a reflexão acerca dos problemas da vida e a investigá-los por meio da observação.

Frente à apresentação para a compreensão acerca da pesquisa escolar, há na seção seguinte a descrição acerca de como se procedeu à realização da investigação, junto aos professores, para o levantamento do que dizem sobre o tema, seguido pelas respectivas análises.

\section{ASPECTOS TEÓRICO-METODOLÓGICOS DA PESQUISA}

Esta investigação utilizou abordagens qualitativa e quantitativa por perceber, conforme Creswell (2010), que o uso combinado de análises possibilita maior compreensão do problema de pesquisa.

A investigação foi realizada com professores do $1^{\circ}$ ao $5^{\circ}$ ano do Ensino Fundamental, considerando um universo de 300 que atuam nas 21 instituições de ensino municipal urbano de uma cidade do interior mineiro. Os docentes foram contatados por intermédio dos diretores e/ou coordenadores pedagógicos e, ao serem convidados para participar da investigação, 124 concordaram. Estes responderam a um questionário, no próprio local de trabalho, contendo as seguintes perguntas: 1) Em sua trajetória como professor você percebe a presença da pesquisa em sua prática no cotidiano escolar? Como e quando? 2) É possível e viável usar a pesquisa em suas aulas? Quais dificuldades e quais facilidades encontradas por você?

Após a transcrição das respostas na íntegra, para análise do material empírico, optou-se pela análise de conteúdo, orientada por estudos de Bardin (2011), que possibilita uma análise categorizada do fenômeno. Posteriormente à leitura dos dados, foi necessária a utilização de um software para organização do conteúdo construído. 
Foi, então, utilizado o software denominado Iramuteq (Interface de $\mathrm{R}$ pour Analyses Multidimensionnelles de Textes et de Questionnaires), inicialmente proposto por Ratinaud (2009), em língua francesa, mas atualmente com dicionários completos em outras línguas. Trata-se de uma ferramenta de apoio para a análise de dados qualitativos de fontes textuais, sendo que entre suas vantagens está a de ser gratuito e na lógica de open source - código aberto, além de ancorado no software $\mathrm{R}$ e na linguagem de programação Python.

O Iramuteq permite cinco tipos de análises: (i) estatísticas textuais clássicas - ETC; (ii) análise de especificidades de grupos; (iii) classificação hierárquica descendente - CHD; (iv) análises de similitude - AS e (v) nuvem de palavras (CAMARGO; JUSTO, 2013), sendo que nesse estudo não foi utilizada a análise de especificidades de grupos.

A análise estatística textual clássica identifica a quantidade de palavras, frequência média e número de hapax (palavra registrada somente uma vez no corpus textual), por meio da redução dos vocábulos com base em sua raiz, e cria uma tabela com os termos em destaque ativos e/ou suplementares (CAMARGO; JUSTO, 2013).

O método de classificação hierárquica descendente postulado por Reinert (1990) organiza o corpus textual em segmentos de texto em função dos seus vocabulários relativos, e o conjunto deles é dividido com base na frequência das formas reduzidas das palavras que foram lematizadas, sendo que o Iramuteq utiliza o software Alceste (CAMARGO; JUSTO, 2013).

A análise de similitude (AS) é baseada na teoria dos grafos, cuja técnica possibilita identificar as coocorrências e indicações de conexidade entre as palavras e, por fim, a nuvem de palavras permite o agrupamento das palavras e organiza os resultados graficamente em função de sua frequência (CAMARGO; JUSTO, 2013).

O projeto de pesquisa foi aprovado pelo Comitê de Ética em Pesquisa da Universidade Federal do Triângulo Mineiro (CEP- UFTM), seguindo as diretrizes da Resolução n 466/2012, sob parecer 1.343.986.

\section{A PESQUISA NA PRÁTICA COTIDIANA DOS PROFESSORES}

A ETC encontrou nas respostas dos professores, sobre a percepção da presença da pesquisa em sua prática no cotidiano escolar, um total de 2.486 palavras sendo que, dessas, 265 (substantivos, adjetivos e verbos) aparecem uma só vez no corpus textual, o que corresponde a 10,66\% das ocorrências dentro do texto e $50,67 \%$ do total de todas as palavras encontradas. Verificou-se que as palavras que mais apareceram nas respostas dos docentes foram: pesquisa (69 vezes), sim (68 vezes), aluno (48 vezes), sala de aula (21 vezes), assunto ( 20 vezes) e conhecimento (17 vezes), como pode ser constatado nos seguintes relatos:

Por muitos anos a pesquisa foi presente em minha prática escolar quando trabalhei na escola, [...], onde trabalhávamos somente com projetos o ano todo. Portanto a pesquisa era constante. Fazia parte da proposta pedagógica da escola. (Professor 66)

Sim, no processo de aprendizado as situações são sempre desafios que exigem pesquisa e construção de novos conhecimentos, tanto para o professor quanto para os alunos. (Professor 81) 
Figura 1. Dendograma do CHD do conteúdo lexical de cada classe

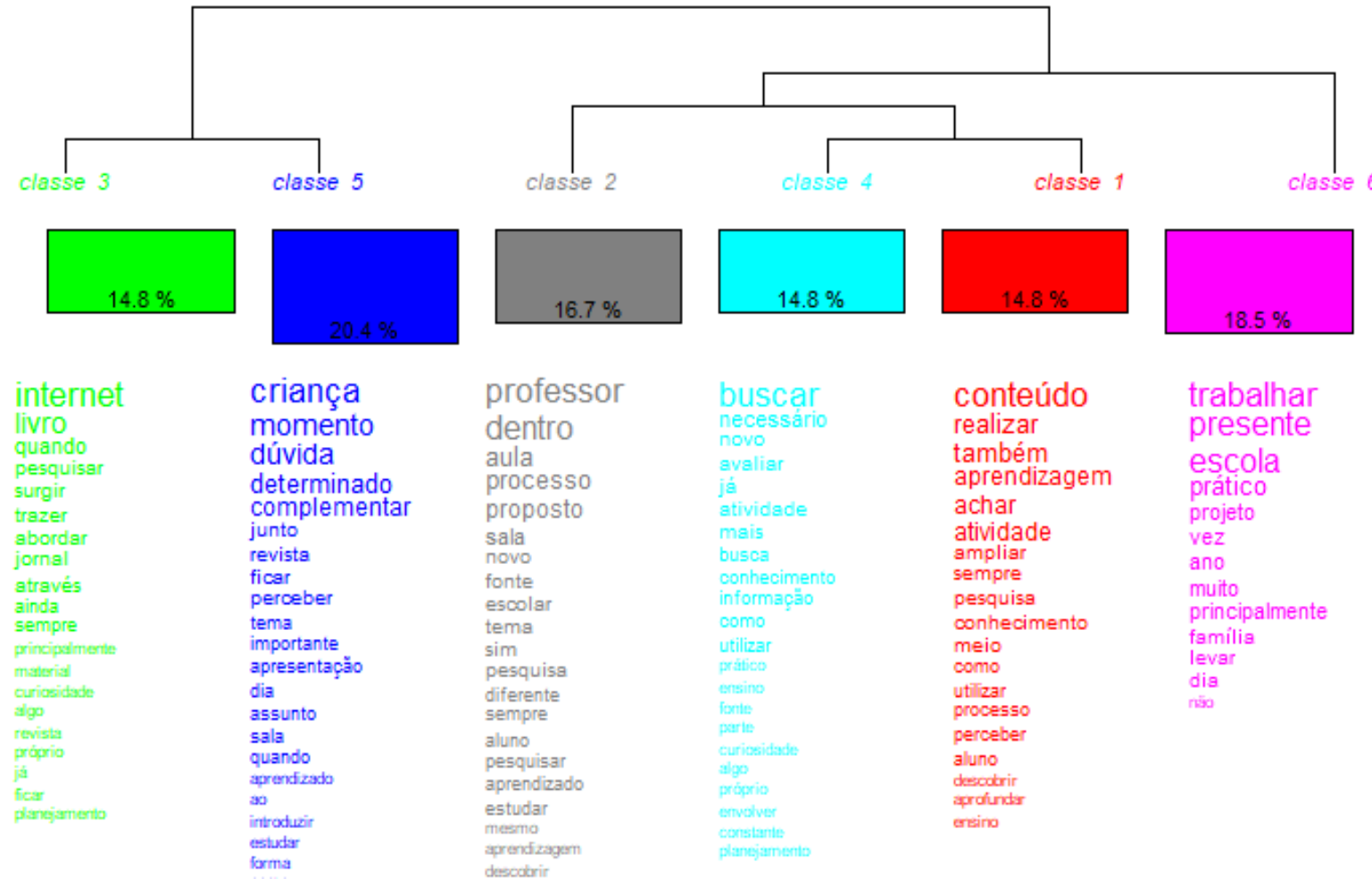

Fonte: Dos autores, com base no software Iramuteq (2018).

O software traz, na CHD (Figura 1), uma categorização na qual foram realizadas divisões sequenciais do corpus e para a qual se originam seis classes de palavras. Essa classificação compreende uma relação das palavras e expressões narradas pelos professores entrevistados. Foram considerados pelo Iramuteq 72 segmentos de texto com 2581 palavras lematizadas que, segundo Marques (2017), consiste no processo linguístico em reduzir uma palavra flexionada à sua parte essencial; foram 450 formas ativas e 178 suplementares, com média de 35,84 por segmento de texto.

O dendograma anteriormente apresentado exibe as palavras-chave de cada classe que se tornaram nítidas pelos trechos dos depoimentos, e exibe marcos que concentram a significação e o sentido dos relatos. Cada classe originada pela CHD é composta pelas palavras com mais significação (maior frequência dentro da classe) e pelas respectivas associações com a classe. Assim pode-se realizar uma possível leitura de cada classe: Classe 1 - O conteúdo da sala de aula pode ser utilizado nas práticas investigativas para aprofundar o conhecimento; Classe 2 - O professor, na sala de aula, pode direcionar a pesquisa como fonte de estudo, a partir de temas, envolvendo o aluno para novos aprendizados; Classe 3 - O pesquisar deve ser propiciado com planejamento e fontes de investigação diversa (internet, livros, jornais); Classe 4 - A avaliação é necessária no processo de busca por novos conhecimentos; Classe 5 A criança possui inúmeras dúvidas que surgem de temas de revistas durante as aulas e Classe $6-\mathrm{O}$ trabalho com a pesquisa deve partir da realidade do aluno, formulando projetos que envolvam a prática no dia a dia, com tentativa de envolvimento da família no processo. 
Figura 2. Representação da análise de similitude

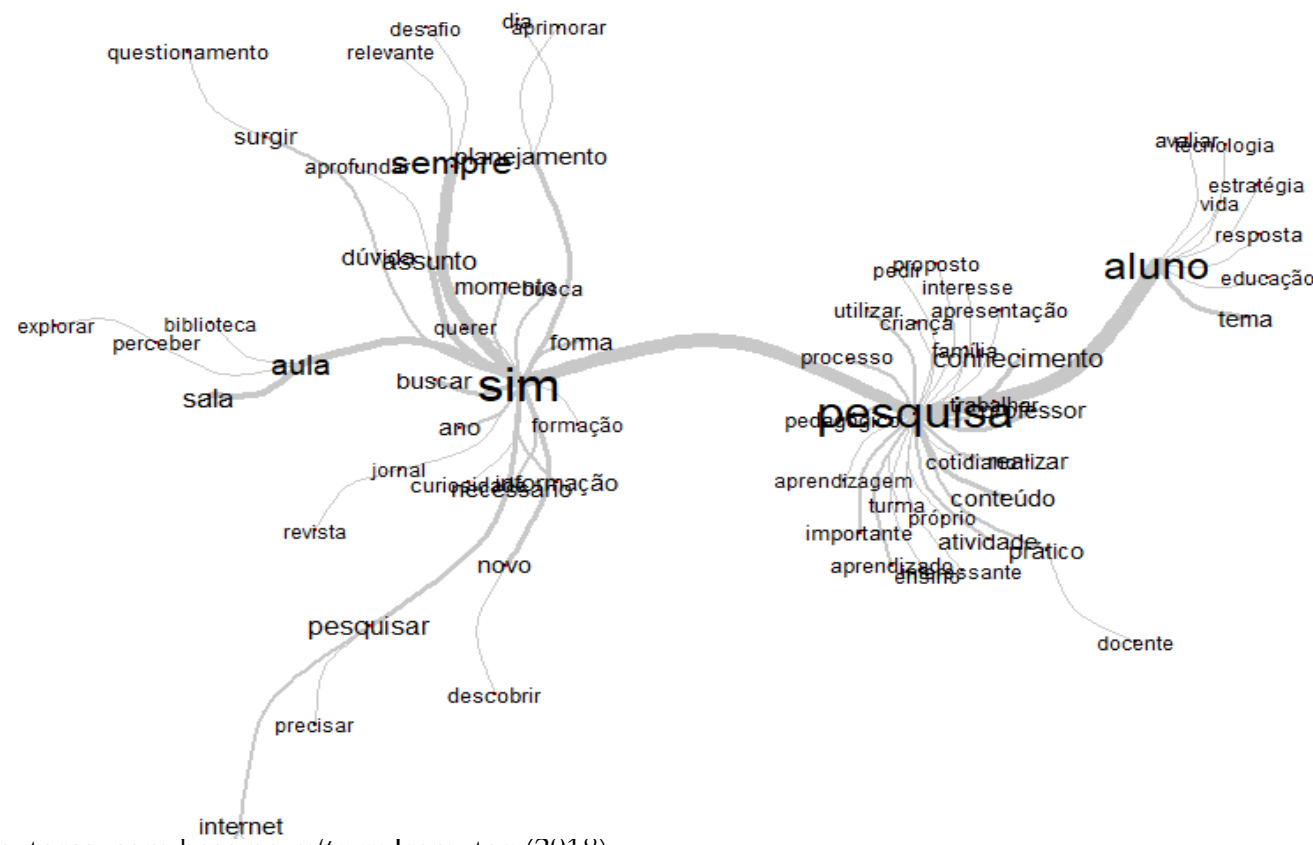

Fonte: Dos autores, com base no software Iramuteq (2018).

O resultado da AS (Figura 2) traz indicações da conexidade entre as palavras e auxilia na identificação da estrutura da representação por meio das ligações entre os termos dentro de cada resposta. É possível verificar as relações evidenciadas nas respostas, as quais mostram como os professores percebem a pesquisa em sua prática cotidiana. Logo, a pesquisa está presente no planejamento de aula dos docentes:

A pesquisa é muito presente na prática do dia a dia, o tempo todo, pois os próprios planejamentos do docente são realizados depois de muita pesquisa. E a pesquisa realizada pelos alunos também, porque para uma melhor fixação do conteúdo, a pesquisa é um recurso muito importante. (Professor 19)

Essa realidade demonstra que a pesquisa é uma forma de construção de novos conhecimentos, ao ampliar os conteúdos ministrados e auxiliar os discentes em seus estudos.

Figura 3. Nuvem de palavras sobre a pesquisa na prática dos docentes

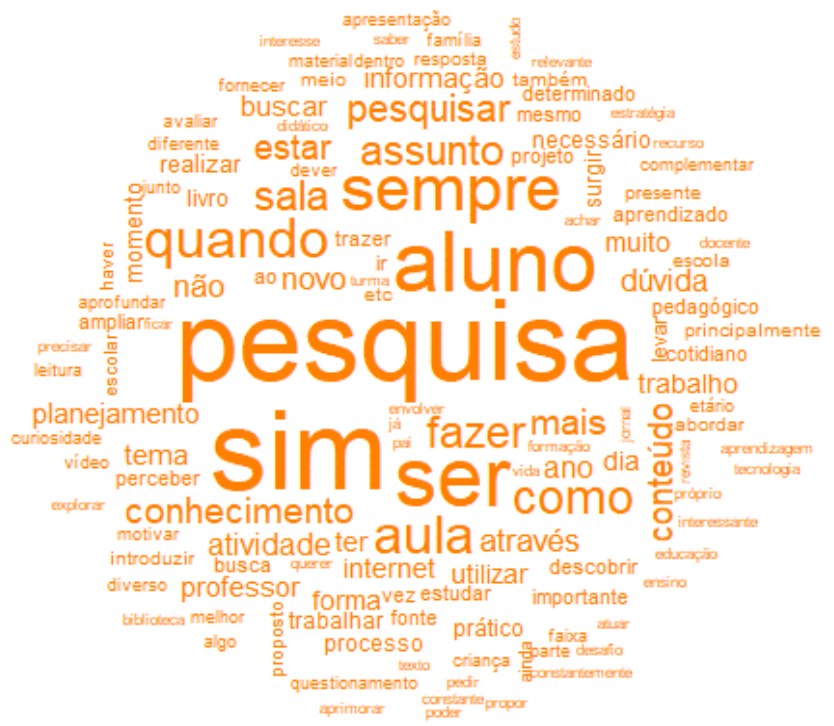

Fonte: Dos autores, com base no software Iramuteq (2018). 
A nuvem de palavras (Figura 3) reforçou que, na percepção da maioria dos professores respondentes, a pesquisa está inserida nas práticas do cotidiano escolar, envolve o aluno e permite construir novos conhecimentos perante as suas dúvidas por meio de variadas fontes de informação, observado pelo destaque das palavras "sim", "pesquisa", "sempre", "aprender" e "aluno". O relato do Professor 99 ratifica esta questão ao dizer: "Sim, dentro dos processos de leitura, desde cedo os alunos precisam compreender que um determinado tema pesquisado engloba todas as disciplinas, então a presença da pesquisa é diária numa sala aula".

Ao analisar as respostas dos professores, ficou evidenciada a utilização da pesquisa na prática cotidiana da sala de aula, assumindo quatro diferentes contextos:

I) A pesquisa como complementação pedagógica de aprendizagem: como um aporte de busca por informações que vão complementar os assuntos discutidos ou conteúdos disciplinares estudados em sala, configura-se como forma de melhorar o aprendizado proporcionado pelos questionamentos, dúvidas e vivências dos alunos. Nunes (2008) destaca que uma educação permanente voltada para a pesquisa requer do professor a incorporação dessa ação da pesquisa em sua prática. $\mathrm{O}$ autor destaca a necessidade de se explorar as dificuldades que advém da relação com o aluno, ao criar hábitos para que se favoreça a necessidade da busca por novos conhecimentos. Adicionalmente deve ater-se a novas compreensões de como ensinar e de realizar suas aulas para que haja um interesse por parte do aluno, não apenas um reprodutivista de conteúdo, mas diversificando suas aulas para levar seus alunos à motivação para o pesquisar.

II) A pesquisa como meio de formação continuada: os docentes utilizam como recurso o planejamento didático para melhorar as aulas, durante as formações em serviço por intermédio da relação entre pedagogos e professores, para elaboração de projetos, como reflexão sobre a prática para futuras modificações. Ser professor, na atualidade, requer curiosidade, deve-se sempre questionar a prática dentro de sala de aula, para que esta seja a mais adequada de modo que o discente possa acompanhar, dialogar e criticar conceitos. O docente necessita ser aberto e buscar novas teorias e conceitos e assumir a conduta de pesquisador, pois desta forma há possibilidades de alterar a ideia reduzida de transmissor e implementador do conhecimento acadêmico para a de investigador, quer de sua prática pedagógica, quer do entorno, de seu cotidiano (OLIVEIRA; GONZAGA, 2012).

III) A pesquisa como forma de buscar por informações e novos conhecimentos no cotidiano: este é enfoque principal para propor pesquisas em sala de aula, com o propósito de induzir os alunos à busca e à construção de novos saberes. Dessa forma, “[...] os educadores passam a considerar o aluno como um sujeito autônomo que organiza sua própria experiência e constrói conhecimento em interação com o mundo e com o outro. É crítico e ativo, autoconfiante, de ação reflexiva" (ALMEIDA, 2006, p. 54).

A pesquisa deve estimular a (re)construção do conhecimento novo (KISTNER, 2008), uma vez que é preciso superar práticas tradicionais centradas na passividade, na mera transmissão de conhecimento, na memorização de conteúdos que não caracterizam um processo educativo de qualidade (OLIGURSKI; PACHANE, 2010). O educando envolvido neste processo tem um crescimento intelectual, altera o modo de se comunicar, bem como o processo de escrita e leitura; passa a ser crítico, adquire autonomia ao apropriar-se da capacidade de argumentar e defender, criticamente, o seu ponto de vista.

IV) Os desafios do exercício da pesquisa na prática da sala de aula: uma parcela de docentes afirmou que não ou pouco estimulam a realização de pesquisa na escola devido a fatores internos ou externos à instituição, a exemplo da assistência familiar para com os trabalhos propostos, escassez de materiais na unidade escolar e a falta de preparo para saberem conduzir os alunos a tal recurso de aprendizagem, particularmente nos anos iniciais do Ensino Fundamental. Os argumentos levantados pelo Professor 114 revelam este aspecto: "Infelizmente não há resultado, pois as famílias acham difícil de realizar juntamente com seus filhos. Ministro aula para crianças de sete anos, não faço uso de pesquisa atualmente".

Oligurski e Pachane (2010), ao realizarem uma investigação exploratória em escolas da cidade de Campinas/SP sobre a pesquisa na prática cotidiana do Ensino Fundamental, perceberam a inexistência desta prática na maioria das unidades. Nas raras vezes em que havia registros, estes se limitavam à 
elaboração de trabalhos acadêmicos descontextualizados de uma visão crítica e criativa e muito menos curiosa para os alunos.

Nesse sentido, entende-se que a pesquisa (ou investigação) que é desenvolvida no campo de trabalho do professor é, antes de mais nada, uma atitude do cotidiano, envolve sempre a busca pela compreensão dos processos de aprendizagem e desenvolvimento referente aos seus educandos, e deve haver autonomia na análise da realidade e dos conhecimentos que compõem seus objetos de ensino (BRASIL, 2001). Oligurski e Pachane (2010, p. 256) corroboram, ainda, com o pensamento:

Compreendemos, então, que a pesquisa confere ao professor uma ótima condição para o exercício da atividade criativa e crítica, em que há questionamento, mas também indicação de soluções para os problemas investigados. Dessa forma, a nosso ver, a pesquisa na área educacional alimenta a atividade de ensino e a atualiza frente à realidade do mundo.

Por fim, Demo (2015) articula que o uso da pesquisa no ambiente escolar é desafiador, compreende inúmeras concepções modernas de professor, definindo-o essencialmente como um mediador do processo na reconstrução de questionamentos e do conhecimento que envolve o aluno, ao guiar o ensino como prática que floresce da pesquisa.

\section{A PESQUISA NA SALA DE AULA: OS DESAFIOS DOS DOCENTES}

Quando indagados sobre "É possível e viável usar a pesquisa em suas aulas? Quais dificuldades e quais facilidades encontradas por você?", a ET mostrou um total de 2.782 palavras sendo que, destas, 287 aparecem uma única vez no corpus textual, o que corresponde a 10,32\% das ocorrências dentro do texto e $53,15 \%$ do total de todas as palavras encontradas. Dessa forma, os vocábulos que mais emergiram nas respostas dos professores foram: aluno (67 vezes), dificuldade (63 vezes), pesquisa (51 vezes), possível (45 vezes) e facilidade (39 vezes). Tais termos podem ser vistos na seguinte narrativa:

Sim, é possível. Porém as dificuldades são alunos de pouca idade e falta de compreensão dos mesmos. As facilidades são curiosidade e interesse deles. (Professor 19)

Figura 4. Dendograma do CHD do conteúdo lexical de cada classe

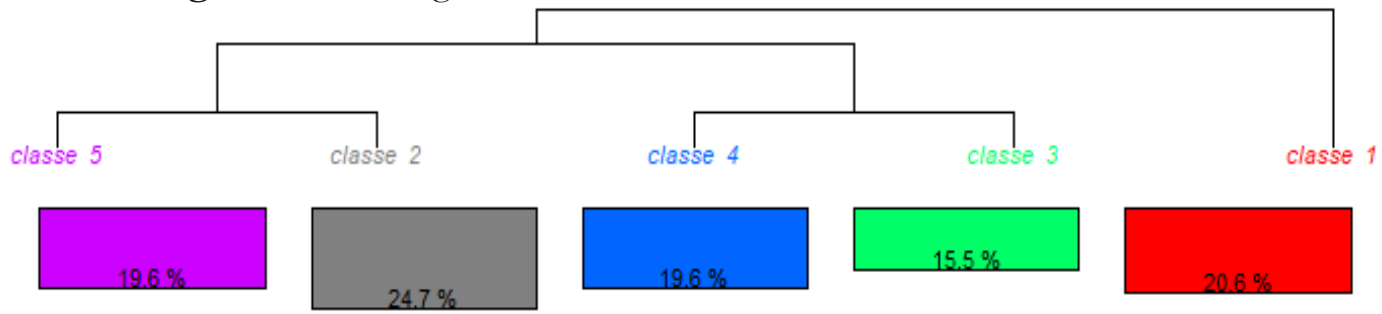

$\begin{array}{lll}\text { informação } & \text { dificuldade } & \text { ano } \\ \text { conhecimento } & \text { facilidade } & \text { auxílio } \\ \text { novo } & \text { interesse } & \text { pesquisa } \\ \text { parte } & \text { material } & \text { turma } \\ \text { recurso } & \text { aluno } & \text { aula } \\ \text { dificultador } & \text { apoio } & \text { criaņa } \\ \text { fonte } & \text { compreensão } & \text { bom } \\ \text { aprendizagem } & \text { tratar } \\ \text { escolar } & \text { envolvimento } & \text { forma } \\ \text { desenvolvimento } & \text { possivel } & \text { dificultar } \\ \text { possibilidade } & \text { ampliar } & \text { viável } \\ \text { grande } & \text { disponivel } & \text { tornar } \\ \text { falta } & \text { relacionado } & \text { achar } \\ \text { contribuir } & \text { curiosidade } & \text { resizas } \\ \text { dfoudsade } & \text { compromisso } & \text { pai } \\ \text { scossa } & \text { messio } & \end{array}$

Fonte: Dos autores, com base no software Iramuteq (2018). 
A análise de CHD (Figura 4) indicou a organização das classes considerando 128 segmentos de texto, com 2.782 palavras lematizadas, 427 formas ativas, 14 suplementares, com média de 21,73 por segmento de texto, sendo considerados $75,78 \%$ dos segmentos de texto para a análise. Há uma divisão dos segmentos de texto em cinco classes, de tal modo a indicar as interpretações acerca dos desafios da pesquisa na sala de aula: Classe 01 - Os meios e recursos de fontes de pesquisa dentro do ambiente escolar (biblioteca, livros, jornais, revistas, internet); Classe 02 - As dificuldades (interesse, compromisso, recursos, materiais) e facilidades (envolvimento, curiosidades, compreensão) na realização de pesquisas; Classe 03 - O trabalho com a pesquisa precisa de incentivo, acompanhamento nas atividades por parte do professor; Classe 04 - A importância da família no processo de pesquisa no início do Ensino Fundamental e Classe 05 - Os recursos da escola postos como desafio para efetivação de práticas investigativas para obtenção de novos conhecimentos.

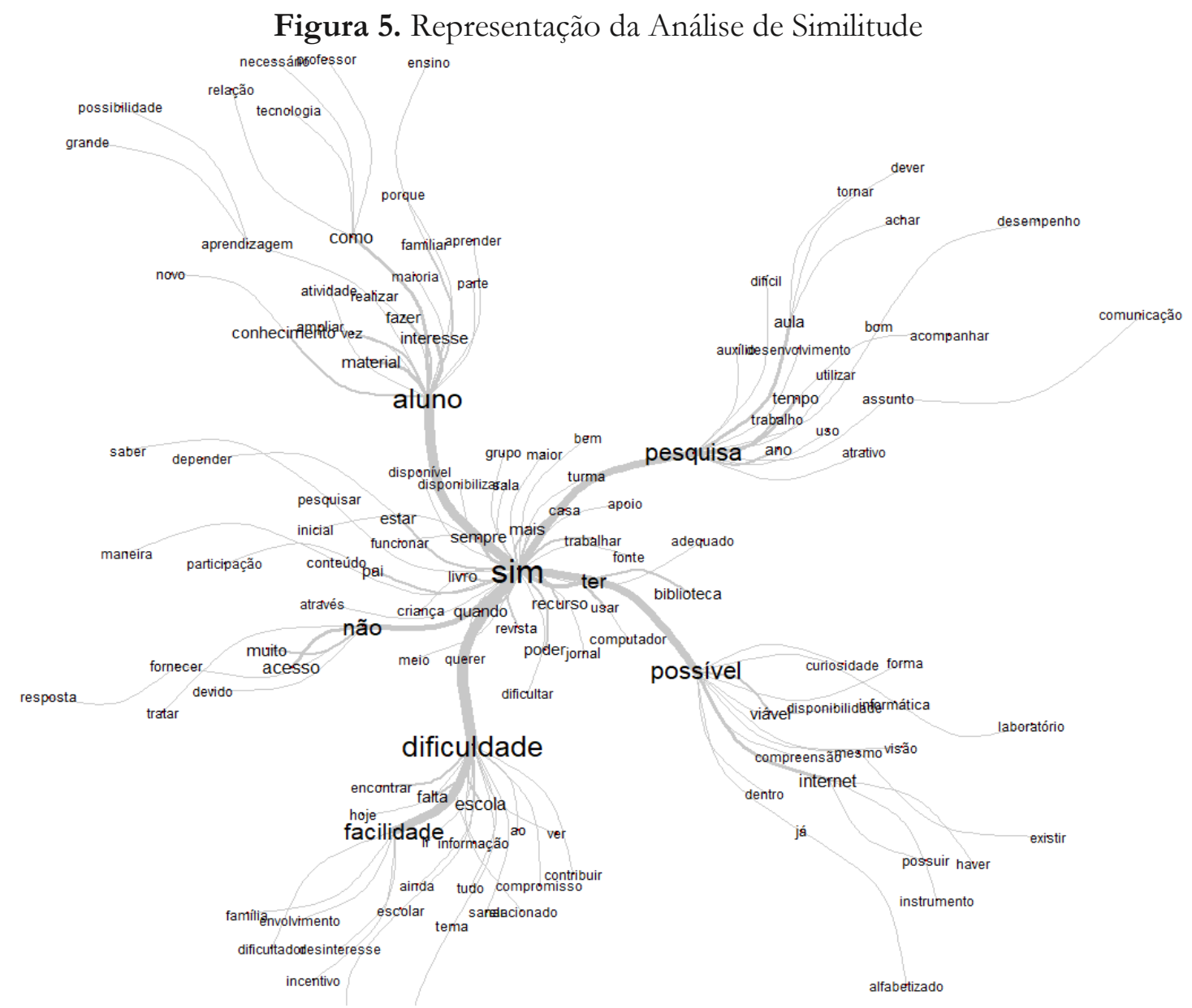

Fonte: Dos autores, com base no software Iramuteq (2018).

É possível analisar, na AS (Figura 5), as conexões que remetem à palavra "sim", demostrando que os professores responderam que é possível e viável articular a pesquisa durante as aulas por eles ministradas. Constata-se que, dentro das possibilidades e viabilidade da pesquisa, precisa haver uma relação estreita da família com as instituições escolares na participação das atividades realizadas pelos alunos. Além disso, os professores apontaram que o interesse dos discentes se faz primordial durante a realização de atividades que envolvam a pesquisa. Em acordo com as respostas dos professores entrevistados:

Sim. Incentivo e participação dos pais é o que dificulta o uso de pesquisa em minhas aulas. Facilidade é poder trabalhar em grupo quando a escola tem projeto em tempo integral. (Professor 31) 
É possível sim. A maior dificuldade é a falta de interesse e muitos alunos não têm acesso a algumas fontes. Usando a curiosidade dos alunos podemos conquistar conhecimentos novos com a pesquisa. (Professor 78)

Figura 6. Nuvem de palavras sobre pesquisa e prática docentes

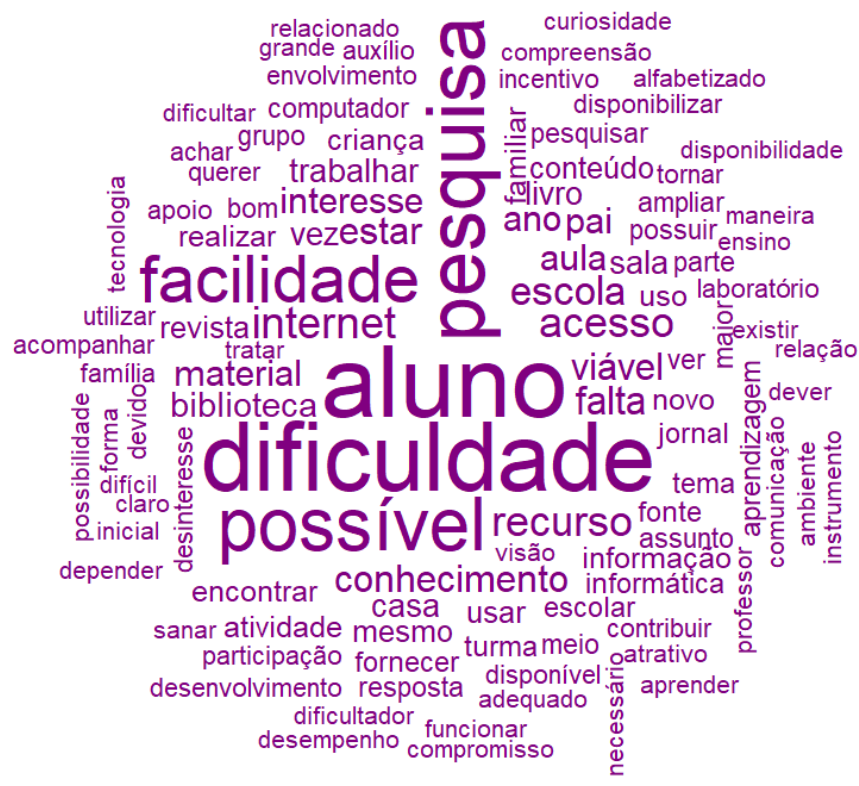

Fonte: Dos autores, com base no software Iramuteq (2018).

A nuvem de palavras (Figura 6) destacou os termos "dificuldade", "aluno", "facilidade" e "pesquisa" como as mais citadas pelos docentes. Repara-se que o vocábulo "dificuldade" possui um destaque maior que seu antônimo, "facilidade". Este aspecto nos faz refletir que as dificuldades encontradas pelos professores são bem acentuadas dentro das unidades escolares para a efetivação do uso da pesquisa em suas aulas, o que remete a fatores como falta de interesse, estrutura familiar e recursos físicos das escolas, conforme pontuam os Professores 05 e 17:

Sim, desde que seja realizada no ambiente escolar, pois existe o dificultador da falta de estrutura familiar e falta de recursos (fonte de pesquisa) em casa. Facilidade quando o aluno é motivado e faz a pesquisa e aprende muito sobre o assunto pesquisado. (Professor 05)

Sim, é possível. A facilidade é quando o aluno prepara seu trabalho e apresenta com critérios para avaliação adequada. A dificuldade que encontramos é quando os computadores [recursos] não estão adequados para a pesquisa. (Professor 17)

Em análise geral foram expostos os desafios encontrados pelos docentes para trabalharem com a pesquisa em suas aulas ou mesmo na escola, a partir dos termos destacados pelo Iramuteq, que revelam as dificuldades (acesso a informações, acompanhamento individual, compromisso discente, controle de anseios, desinteresse do aluno, disciplina em sala, escolha de temáticas, estrutura familiar, falta de biblioteca, fontes de pesquisa, fracasso escolar, hábito da pesquisa, hábitos de leitura, imaturidade do educando, número de alunos, organização do currículo, pesquisa de campo, recursos físicos, recursos tecnológicos físicos, tempo de acompanhamento, tempo para realização, uso do dicionário).

Mostram as facilidades (acessibilidade das informações, ampliar conhecimentos, auxílio para aprendizagem, curiosidade de assuntos, empenho do aluno, fontes de pesquisa, formação continuada, meios de comunicação, metodologia de ensino, motivação discente, participação ativa, prazer pelo novo, recursos tecnológicos, trabalho interdisciplinar, uso da biblioteca).

Tais desafios apontados pelas análises convergem com os estudos realizados por Oliveira e Campello (2016). Desta forma esses aspectos variam de acordo com a estruturação das instituições escolares nas quais os docentes atuam: a) recursos/materiais/fontes para realização da pesquisa, b) 
recursos tecnológicos nas escolas e em casa, c) interesse dos alunos para a pesquisa, d) uso da biblioteca com ambiente próprio para práticas investigativas.

Esses apontamentos mostraram que deve haver uma reestruturação dos currículos e dos espaços nas escolas, além da reorganização do tempo, para dar mais autonomia aos professores de modo que possam trabalhar a pesquisa em sala de aula, além de rever o uso dos de fontes, recursos e materiais que estruturam as unidades escolares para oferecer qualidade aos docentes para realização de seus trabalhos: assim, os investimentos municipais e estaduais se fazem necessários.

Contudo, também cabe ao professor rever suas práticas de ensino quanto ao desinteresse do aluno, uma vez que não há sentido em recomendar uma pesquisa para se trabalhar com determinado conteúdo, apenas pontualmente e sem finalidade pedagógica. A motivação, como a literatura menciona neste estudo, é algo fundamental para engajar o aluno em práticas investigativas. Em acordo com os relatos dos Professores 37, 44, 86 e 106:

Sim, é possível. A escola possui fontes para pesquisa como biblioteca, laboratório de informática, livros didáticos e paradidáticos. A dificuldade encontrada é administrar o tempo em relação à faixa etária em que atuo. (Professor 37)

Em alguns conteúdos sim, plantas, animais, sistema monetário, sólidos geométricos, acho que em tudo. Dificuldades, apoio dos pais. Facilidades, interesse dos alunos e recursos tecnológicos da escola. (Professor 44)

Uso a pesquisa algumas vezes, porque não temos muitos materiais disponíveis, os nossos alunos têm uma realidade de vida difícil onde precisamos de muito trabalho para estimulá-los. (Professor 86)

Sim. O interesse do aluno é a principal barreira para que seja feita e apresentada uma boa pesquisa. (Professor 106)

Corroborando com essa análise, no estudo realizado por Lima (2016), com professores do Ensino Médio em dois municípios cearenses, Maracanaú e Fortaleza, a autora destaca as mesmas dificuldades apresentadas no quadro pelos professores dos anos iniciais do Ensino Fundamental que participaram de nossa pesquisa: o tempo, organização do currículo, recursos nas escolas, a falta de auxílio dos pais nas atividades de pesquisa, a utilização de fontes de pesquisa, hábitos de estudos, o interesse dos alunos, uso das bibliotecas etc. Para a autora, estas dificuldades acentuam o papel de descrença que a escola tem assumido na atualidade. Lima (2016, p. 149) ratifica afirmando que se infere ao professor mais uma atribuição além daquelas que a condição da educação brasileira os permite fazer, correndo o risco de tornar o professor pesquisador o redentor dos problemas educacionais.

Percebe-se que deve haver uma reestrutura dos currículos nas escolas e a organização do tempo, para dar mais autonomia aos professores de modo que possam trabalhar a pesquisa em sala de aula, além de rever o uso dos de fontes, recursos e materiais que estruturam as unidades escolares para oferecer qualidade aos docentes para realização de seus trabalhos, e uma das formas é a partir de investimentos municipais e estaduais. Contudo, também cabe ao professor rever suas práticas de ensino quanto a desinteresse do aluno, uma vez que não há sentido em recomendar uma pesquisa apenas como "enfeite" a mais para trabalhar com determinado conteúdo. A motivação, como a literatura menciona neste estudo, é algo fundamental para ensejar o aluno a práticas investigativas.

As análises de dados por meio dos dendogramas, análises de similitude e nuvens de palavras, ao seu final, indicam que os docentes compreendem a pesquisa na sala de aula como recurso benéfico às práticas docentes, fazendo com que os alunos tenham vivência com projetos e atividades relacionados a práticas investigativas. As experiências concretizadas em sala de aula interferem no ensino-aprendizagem e permitem mudanças significativas em aspectos atitudinais ou cognitivos, especialmente porque o trabalho com a pesquisa proporciona sentido às práticas escolares e possibilita a aprendizagem de forma mais lúdica. Além disso, os professores entendem que esses estudantes, ao se sentirem motivados para o processo de pesquisa, realizam as atividades escolares com maior interesse para buscar por novas informações ou novos conhecimentos. 


\section{CONSIDERAÇÕES FINAIS}

Durante o estudo realizado ficou evidenciado pelos docentes que a pesquisa escolar contribui para o desenvolvimento de atitudes mais críticas, curiosas e reflexivas na interpretação da realidade, por meio dos questionamentos que emergem de assuntos contextualizados. Possuem uma visão eficiente da relação entre professor e aluno no processo de ensino ao promover um ambiente escolar desafiador, no qual a formação de habilidades e competências do próprio aluno são pontos primordiais na construção de sua autonomia. Apontaram que o acompanhamento é um fator preponderante durante a realização de práticas investigativas pelo aluno.

Quanto às facilidades e dificuldades da pesquisa escolar na prática pedagógica notaram-se os inúmeros desafios que os professores apontam ao trabalharem com pesquisa em suas aulas. Dentre todos os excertos ilustrados neste estudo, o interesse dos alunos, o tempo e a estrutura das escolas mostram que a educação precisa ser repensada quanto ao currículo para os alunos.

Com o objetivo de propiciar momentos de práticas de pesquisa, os docentes sempre estão revendo os seus planejamentos de aula para incluí-los com recursos que tragam novos ou reconstruam conhecimentos e nas formações continuadas que tracem projetos que culminem com a prática do dia a dia, de modo a sair dos discursos para transformá-los em uma cultura dentro da escola.

Nesta investigação revelou-se um ensinar pela pesquisa, que a literatura traz não apenas como um modismo, os professores sabem das reais modificações que esse método proporciona na educação de seus alunos, admitem que a pesquisa é ato político, que possibilita ao indivíduo a oportunidade de ser um sujeito social, com perspectivas de libertar-se para novos conhecimentos e questionamentos, de desenvolver a autonomia e a curiosidade na busca constante, garantindo a formação efetiva para cidadania.

O estudo não teve intenção de desqualificar o trabalho que as escolas e os professores promovem, a pretensão nunca foi de arrolar juízos de valor quanto às práticas docentes, mas de refletir sobre como se processa o ensino direcionado com a pesquisa dentro das instituições de ensino, a partir do olhar dos professores. Há consciência do esforço dos educadores em promover atividades pontuais dentro das instituições, mesmo entendendo que ainda não seriam as ideais; contudo, a semente deve ser plantada e o cuidado para que ela produza bons frutos depende da força coletiva dos professores.

Por fim, este estudo abre um leque de trabalhos futuros ao permitir continuar as investigações acerca da pesquisa na Ciência da Informação para a Formação Continuada, Tecnologias Educacionais e Múltiplas Aprendizagens e Currículos Inovadores para Sala de Aula, ao tentar indicar caminhos para os docentes tendo em vista o ensino-aprendizagem dos alunos frequentes nos anos iniciais do Ensino Fundamental.

\section{REFERÊNCIAS}

ALMEIDA, S. C. D. A pesquisa escolar no processo ensino aprendizagem: avaliando limites e possibilidades. 2006. 114 p. Dissertação (Mestrado) - Pontifícia Universidade Católica do Paraná, Curitiba, 2006.

ARAÚJO, M.S.T.; ABIB, M.L.V. Atividades experimentais no ensino de Física: diferentes enfoques, diferentes finalidades. Revista Brasileira de Ensino de Física, São Paulo, v. 25, n. 2, p. 176-194, 2003.

ASSIS, A.; TEIXEIRA, O. P. B. Argumentações discentes e docente envolvendo aspectos ambientais em sala de aula: uma análise. Ciência e Educação, Bauru, 2009, v. 15, n. 1, p. 47-60.

BAGNO, M. Pesquisa na escola: o que é, como se faz. 22. ed. São Paulo: Edições Loyola, 2008.

BARDIN, L. Análise de conteúdo. São Paulo: Edições 70, 2011. 
BRASIL. Lei $\mathbf{n}^{\circ} \mathbf{9 . 3 9 4}$ de 20 de dezembro de 1996. Estabelece as Diretrizes e Bases da Educação Nacional. Brasília, 1996.

BRASIL. Parecer CNE/CP $\mathbf{n}^{\mathbf{0}}$ 9/2001. Diretrizes Curriculares Nacionais para a Formação de Professores da Educação Básica, em nível superior, curso de licenciatura, de graduação plena. Brasília, 2001.

CAMARGO, B. V.; JUSTO, A. M. Iramuteq: tutorial para uso do software de análise textual. Florianópolis: Laboratório de Psicologia Social da Comunicação e Cognição - LACCOS, Universidade Federal de Santa Catarina, Brasil, 2013.

CARVAlHO, A. M. P. Ensino de ciências: unindo a pesquisa e a prática. São Paulo: Editora Thompson. 2004.

CARVALHO, A. M. P. et al. Ensino de ciências e a proposição de sequências de ensino investigativas. In: CARVALHO, A.M.P. (Org.). Ensino de Ciências por Investigação. São Paulo: Cengage Learning, 2013, p. 1-20.

CRESWELL, J. W. Projeto de pesquisa: métodos qualitativo, quantitativo e misto. Porto Alegre: Artmed, 2010.

DEMO, P. Educar pela pesquisa. 10. ed. Campinas: Autores Associados, 2015.

DEMO, P. Pesquisa e construção do conhecimento: metodologia científica no caminho de Habermas. Rio de Janeiro: Tempo Brasileiro, 1994.

DINIZ-PEREIRA, J. E.; LACERDA, M. P. Possíveis significados da pesquisa na prática docente: ideias para fomentar o debate. Revista Educação e Sociedade, Campinas, v. 30, n. 109, p. 1229-1242, 2009.

GALIAZZI, M. C.; MORAES, R. Educação pela pesquisa como modo, tempo e espaço de qualificação da formação de professores de ciências. Ciência e Educação, Bauru, v. 8, n. 2, p. 237-252, 2002.

GRABAUSKA, C. J.; BASTOS, F. P. Investigação-ação educacional: possibilidade crítica e emancipatórias na prática educativa. In: MION, R.A.; SAITO, C. H. Investigação-Ação: mudando o trabalho de formar professores. Ponta Grossa: Gráfica Planeta, 2001, p. 48-62.

HERNANDÉZ, F. Transgressão e mudança na educação: os projetos de trabalho. Porto Alegre, Artes Médicas, 1998.

KISTNER, I. C. C. O professor e a pesquisa: uso em sala de aula. 2008. 269 f. Dissertação (Mestrado) - Programa em Educação, Universidade Católica de Santos, Santos, 2008.

LIMA, L. S. Professores que ensinam com pesquisa na Educação Básica: um estudo no Ensino Médio. 2016. 186 f. Dissertação (Mestrado) - Centro de Educação, Universidade Estadual do Ceará, Fortaleza, 2016.

MARQUES, M. K. Entrelaçando caminhos: histórias de vida dos professores de música em Fortaleza. 2017. 150 f. Tese (Doutorado) - Programa de Pós-graduação em Educação Brasileira, Universidade Federal do Ceará, Fortaleza, 2017.

MARTINS, J. S. Projetos de pesquisa: estratégias de ensino e aprendizagem em sala de aula. Campinas: Armazém do Ipê (Autores Associados), 2005. 
MOURA, D. G.; BARBOSA, E. F. Trabalhando com projetos: planejamento e gestão de projetos educacionais. Petrópolis: Vozes, 2007.

MUNFORD D.; LIMA M. E. Ensinar ciências por investigação: em que estamos de acordo? Ensaio Pesquisa em Educação em Ciências, Belo Horizonte, v. 9, n. 1, p. 89-111, 2007.

NININ, M. O. G. Pesquisa na escola: que espaço é esse? O do conteúdo ou o do pensamento crítico? Educação em Revista, Belo Horizonte, n. 48, p. 17-35, 2008.

NOGUEIRA, N. R. Pedagogia dos projetos: uma jornada interdisciplinar rumo ao desenvolvimento das múltiplas inteligências. São Paulo: Érica. 2003.

NUNES, D. R. P. Teoria, pesquisa e prática em Educação: a formação do professor-pesquisador. Educação e Pesquisa, São Paulo, v. 34, n. 1, p. 97-107, 2008.

OLIGURSKI, E. M.; PACHANE, G. G. A possibilidade de incorporar uma pesquisa na prática cotidiana do professor do ensino fundamental. Educação em Revista, Belo Horizonte, v. 26, n. 2, p. 249-275, 2010.

OLIVEIRA, A. M. O professor e a pesquisa na Educação Básica: propostas para aprender a aprender. 2015. 146 f. Dissertação (Mestrado) - Mestrado Profissional em Ensino de Ciências Exatas, Programa de Pós-Graduação Stricto Sensu, Centro Universitário Univates, Lajeado, 2015.

OLIVEIRA, C. B.; GONZAGA, A. M. Professor pesquisador - educação científica: o estágio com pesquisa na formação de professores para os anos iniciais. Ciência e Educação, Bauru, v. 18, n. 3, p. 689-702, 2012.

OLIVEIRA, I. R.; CAMPELLO, B. S. Estado da arte sobre pesquisa escolar no Brasil. Transinformação, Campinas, v. 28, n. 2, p. 181-194, 2016.

PANIAGO, R. N.; ROCHA, S. A. da; PANIAGO, J. N. A pesquisa como possibilidade de ressignificação das práticas de ensino na escola no/do campo. Ensaio: Pesquisa em Educação em Ciências, Belo Horizonte, v. 16, n. 1, p. 171-188, 2014.

PENA, F. L. A.; RIBEIRO FILHO, A. Obstáculos para o uso da experimentação no ensino de Física: um estudo a partir de relatos de experiências pedagógicas brasileiras publicados em periódicos nacionais da área (1971-2006). Revista Brasileira de Pesquisa em Educação em Ciências, Belo Horizonte, v. 9, n. 1, p. 1-13, 2009.

PERTICARRARI, A. et al. O uso de textos de divulgação científica para o ensino de conceitos sobre ecologia a estudantes da educação básica. Ciência e Educação, Bauru, v. 16, n. 2, p. 369-386, 2010.

PIETROCOLA, M. Construção e realidade: o papel do conhecimento físico no entendimento do mundo. Florianópolis: UFSC, 2005.

RATINAUD, P. IRAMUTEQ: Interface de R pour les Analyses Multidimensionnelles de Textes et de Questionnaires [Computer software]. 2009. Disponível em: http://www.iramuteq.org

REINERT, M. Alceste, une méthodologie d'analyse des données textuelles et une application: Aurelia de Gerard de Nerval. Bulletin de Methodologie Sociologique, Toulouse, v. 26, p.24-54, 1990. 
VASCONCELOS, C.; PRAIA, J. F.; ALMEIDA, L. S. Teorias de aprendizagem e o ensino/aprendizagem das ciências: da instrução à aprendizagem. Psicologia Escolar e Educacional, Campinas, v. 7, n. 1, p. 11-19, 2003.

ZANOLLA, J. J. Pedagogia de projetos como ferramenta metodológica na formação inicial de professores de Física. 2008. 165f. Dissertação (Mestrado em Educação). Programa de Pós-graduação em Educação, UEPG, Ponta Grossa, 2008.

ZÔMPERO, A. F.; LABURÚ, C. E. Atividade investigativa no ensino de ciências: aspectos históricos e diferentes abordagens. Ensaio: Pesquisa em Educação em Ciências, Belo Horizonte, v. 13, n. 3, 2011.

Submetido: $26 / 05 / 2019$

Aprovado: 25/09/2019 